\title{
The influence of soft-tissue volume grafting on the maintenance of peri-implant tissue health and stability
}

\author{
Karina Obreja ${ }^{1}$, Ausra Ramanauskaite ${ }^{1 *}$, Amira Begic ${ }^{1}$, Maria Elisa Galarraga-Vinueza ${ }^{2}$, Puria Parvini ${ }^{1 \dagger}$ and \\ Frank Schwarz ${ }^{1+}$
}

\begin{abstract}
Background: To investigate the influence of soft-tissue volume grafting employing autogenous connective tissue graft (CTG) simultaneous to implant placement on peri-implant tissue health and stability.

Material and methods: This cross-sectional observational study enrolled 19 patients ( $n=29$ implants) having dental implants placed with simultaneous soft-tissue volume grafting using CTG (test), and 36 selected controls ( $n=55$ implants) matched for age and years in function, who underwent conventional implant therapy (i.e., without soft-tissue volume grafting). Clinical outcomes (i.e., plaque index (PI), bleeding on probing (BOP), probing depth (PD), and mucosal recession (MR)) and frequency of peri-implant diseases were evaluated in both groups after a mean follow-up period of $6.15 \pm 4.63$ years.

Results: Significant differences between test and control groups at the patient level were noted for median BOP (0.0 vs. 25.0\%; $p=0.023$ ) and PD scores ( 2.33 vs. $2.83 \mathrm{~mm} ; p=0.001)$, respectively. The prevalence of peri-implant mucositis and peri-implantitis amounted to $42.1 \%$ and $5.3 \%$ in the test and to $52.8 \%$ and $13.9 \%$ in the control group, respectively.

Conclusion: Simultaneous soft-tissue grafting using CTG had a beneficial effect on the maintenance of periimplant health.
\end{abstract}

Keywords: Soft-tissue grafting, Peri-implant diseases, Dental implants

\section{Introduction}

A major goal of implant therapy is to ensure long-term peri-implant tissue health and create appealing esthetics. To obtain these therapeutic endpoints, soft-tissue grafting procedures performed either simultaneously with or after implant placement have become an indispensable part of contemporary implant dentistry [1].

\footnotetext{
* Correspondence: ramanauskaite@med.uni-frankfurt.de

${ }^{\dagger}$ Puria Parvini and Frank Schwarz equally contributed to the present study and are considered joint last authors.

'Department of Oral Surgery and Implantology, Johann Wolfgang Goethe-University Frankfurt, Carolinum, Theodor-Stern-Kai 7; Building 29, 60596 Frankfurt, Germany

Full list of author information is available at the end of the article
}

From a biological point of view, a lack of or reduced height $(<2 \mathrm{~mm})$ of keratinized mucosa (KM) around the implants was shown to jeopardize self-performed oral hygiene measures, which subsequently increased the likelihood of soft-tissue inflammation $[1,2]$. As a consequence, soft-tissue grafting procedures aimed at increasing keratinized tissue have been shown to markedly improve peri-implant soft-tissue inflammatory conditions and were associated with higher marginal bone levels compared to the control sites [3]. Moreover, from an esthetic perspective, the presence of $\mathrm{KM}>2 \mathrm{~mm}$ was demonstrated to be a preventive measure for the occurrence of peri-implant soft-tissue dehiscences [4].

Changes in peri-implant soft-tissue height, particularly on the facial aspect, are a critical factor that may

\section{Springer Open}

(c) The Author(s). 2021 Open Access This article is licensed under a Creative Commons Attribution 4.0 International License, which permits use, sharing, adaptation, distribution and reproduction in any medium or format, as long as you give appropriate credit to the original author(s) and the source, provide a link to the Creative Commons licence, and indicate if changes were made. The images or other third party material in this article are included in the article's Creative Commons licence, unless indicated otherwise in a credit line to the material. If material is not included in the article's Creative Commons licence and your intended use is not permitted by statutory regulation or exceeds the permitted use, you will need to obtain permission directly from the copyright holder. To view a copy of this licence, visit http://creativecommons.org/licenses/by/4.0/. 
compromise the overall esthetic result of implantsupported restoration [5]. A thin mucosa (also known as a soft-tissue biotype) at the time of implant installation was found to be a crucial component that correlated with facial soft-tissue recession [6-8]. In fact, to attenuate the undesirable changes of the soft-tissue margin, soft-tissue volume augmentation at the time of implant placement was also suggested as a preventive measure $[9,10]$. On the contrary, currently available data evaluating procedures to increase mucosal thickness did not show any significant effects on bleeding scores, but higher interproximal marginal bone levels over time when compared with control sites [1]. Due to a lack of reporting, an evaluation of the prevalence of periimplant disease was not feasible [1].

Therefore, the aim of the present cross-sectional analysis was to assess the influence of soft tissue volume grafting on the peri-implant tissue health and stability.

\section{Materials and methods}

The present investigation was designed as an observational, cross-sectional case-control study evaluating the clinical treatment outcomes of implants inserted simultaneously with (test group) and without (control group) soft-tissue volume augmentation. All patients had received the same implant brand (Ankylos ${ }^{\circ}$, Dentsply Sirona Implants, Hanau, Germany) in a single university clinic (Department of Oral Surgery and Implantology, Goethe University, Frankfurt) and were recruited during their yearly maintenance visits.

Patients were included in the study once they were informed about the investigation procedures and gave their written informed consent. The procedures in the present study were in accordance with the Declaration of Helsinki, as revised in 2013, and the study protocol was approved by the local ethics committee (registration number: 78/18).

\section{Patient selection criteria}

The following inclusion criteria were applied for patient selection:

- Patients with $>18$ years of age rehabilitated with at least one Ankylos implant;

- Patients with treated chronic periodontitis and proper periodontal maintenance care;

- Non-smokers, smokers and former smokers;

- A good level of oral hygiene as evidenced by a plaque index $(\mathrm{PI})<1$ at the implant level; and

- Attendance of yearly routine implant maintenance appointment.

Patients were excluded for the following conditions: the presence of combined endodontic-periodontal lesions; systemic diseases that could influence the outcome of the therapy, such as diabetes (HbA1c > 7), osteoporosis and antiresorptive therapy; a history of malignancy, radiotherapy, chemotherapy, or immunodeficiency; and pregnancy or lactation at the last follow-up.

\section{Surgical protocol}

Soft-tissue biotype was assessed preoperatively based on the probe's transparency at the mid-facial aspect and categorized as thin when the probe was visible and thin when it was not visible. Two-piece platform-switched implants were placed $2-3 \mathrm{~mm}$ subcrestally according to the manufacturer's surgical protocol. Implants in the control group exhibited a thick soft-tissue biotype and therefore underwent a conventional placement protocol (i.e., without soft-tissue volume grafting; Fig. 1a).

Implants in the test group presented with a thin softtissue biotype, and therefore, a connective tissue graft (CTG) harvested from the hard palate was simultaneously applied on the facial aspect via tunneling technique (Fig. 1b and Fig. 2). All surgeries were performed by one experienced oral surgeon (PP).

\section{Implant and implant-site characteristics}

The following study variables were assessed for the test and control implant sites: (1) implant age (i.e., defined as time after implant placement), (2) implant location in the upper jaw, and (3) implant diameter.

\section{Clinical measurements}

The following clinical parameters were registered at each implant site using a periodontal probe: (1) plaque index (PI) (Löe et al., 1967); (2) bleeding on probing (BOP)measured as presence/absence; (3) probing depth (PD) measured from the mucosal margin to the probable pocket; (4) mucosal recession (MR) - measured from the restoration margin to the mucosal margin; and (5) keratinized mucosa (KM) (mm)-measured on the buccal aspects of the implants.

PI, BOP, PD, and MR measurements were performed at six aspects per implant site: mesiobuccal $(\mathrm{mb})$, midbuccal (b), distobuccal (db), mesiooral (mo), midoral (o), and distooral (do). KM measurement was performed at three aspects per implant site: mesiobuccal (mb), midbuccal (b), and distobuccal (db).

The presence of peri-implant diseases at each implant site was assessed as follows [11]:

- Peri-implant mucositis defined as the presence of BOP and/or suppuration with on gentle probing with or without increased PDs compared to previous examinations and an absence of bone loss beyond crestal bone level changes resulting from initial bone remodeling.

- Peri-implantitis defined as the presence of BOP and/ or suppuration on gentle probing, increased PDs 
a
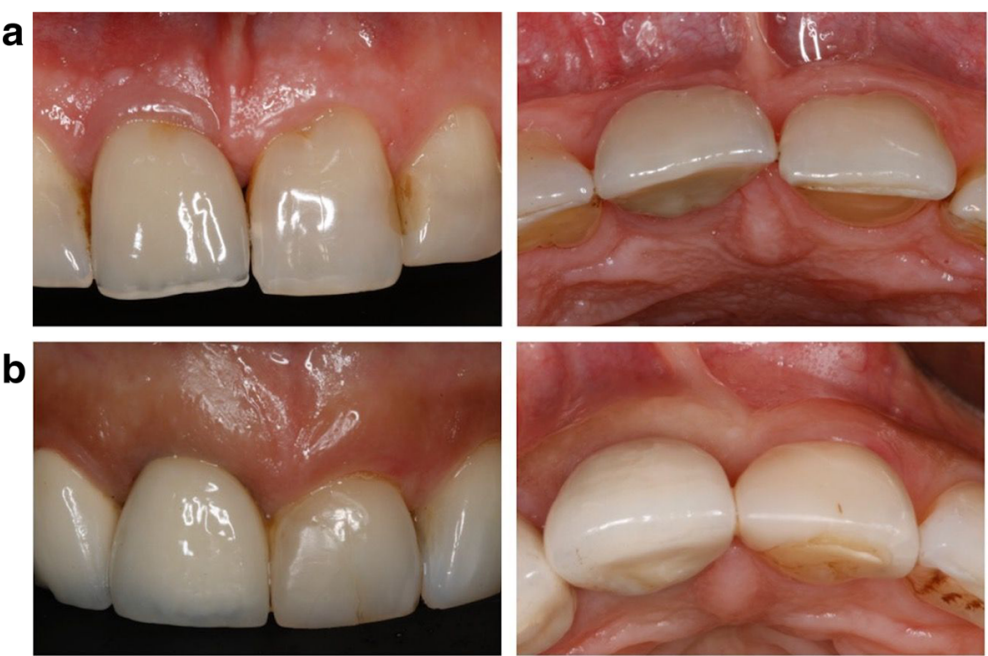

Fig. 1 a Clinical view of implant 011 at 6 years of healing (control group). b Clinical view of implant 0115 years following soft-tissue volume grafting (test group)

compared to previous examination, and the presence of bone loss beyond crestal bone level changes resulting from initial bone remodeling.

Radiographs (i.e., panoramic) were just taken when clinical signs suggested the presence of peri-implant tissue inflammation (i.e., the presence of BOP). To estimate the bone level changes at the respective implant sites, these radiographs were compared with those taken following the placement of the final prosthetic reconstruction (i.e., baseline).

\section{Investigators meeting and calibration}

Prior to the start of the study, a calibration meeting was held with each examiner ( $\mathrm{KO}, \mathrm{AB}, \mathrm{AR})$ to standardize (pseudonymous) data acquisition and the assessment of study variables. For the calibration of the examiners, double measurements were performed with a 5 -min interval of the assessed clinical parameters in 5 patients with a total of 15 implants. The calibration was acceptable when repeated measurements were similar $>95 \%$ level. The documentation of demographic study variables, implant sites' characteristics, and clinical measurements were documented using a generated standardized data extraction template.

\section{Statistical analysis}

The statistical analysis was performed using a commercially available software program (SPSS Statistics 27.0: IBM Corp., Ehningen, Germany). Descriptive statistics (means, standard deviations, medians and 95\% confidence intervals) were calculated for $\mathrm{mPI}$, BOP, PD, and MR values. The analysis was performed at the patient and implant levels. The data were tested for normality by means of the Shapiro-Wilk test. Comparisons of clinical parameters between the test and control groups were performed by employing the Mann-Whitney $U$ test. Linear regression analyses were used to depict the relationship between mean $\mathrm{BOP}, \mathrm{PD}$, and MR values and KM scores. The alpha error was set at 0.05 .
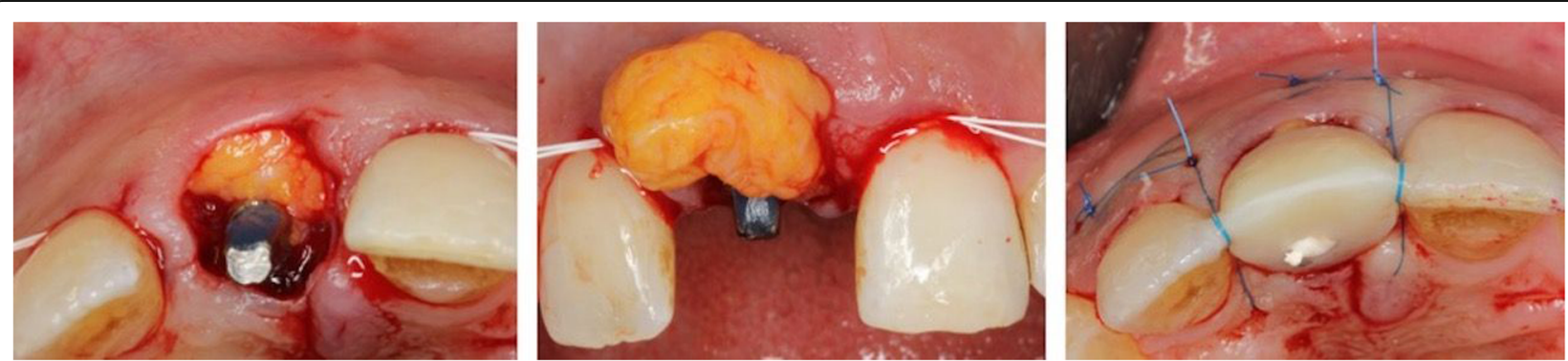

Fig. 2 Clinical illustration of soft-tissue grafting procedure. $\mathbf{a}, \mathbf{b}$ Connective tissue graft harvested from the hard palate was positioned on the facial aspect via tunneling technique at implant 011. c Occlusal view of the surgical site 


\section{Results}

\section{Patient and implant sites' characteristics}

The test group included 19 patients (13 women and 6 men) with a total of 29 implants, whereas the control group included 36 patients (20 women and 16 men) with a total of 55 implants. Mean patient age in the test and control groups was $46.24 \pm 18.48$ and $62.21 \pm 14.41$ years, respectively. The mean implant functioning time was $4.16 \pm 2.06$ years for the test group and $7.19 \pm 5.25$ years for the control group. All implants in the test group revealed a diameter of $3.5 \mathrm{~mm}$ with an equal distribution between all regions investigated. In the control group, the most frequent diameter was also $3.5 \mathrm{~mm}$ (85.5\%), with a predominant implant location in the region of the lateral and central incisors (Table 1).

\section{Clinical measurements}

The results of the clinical measurements are presented in Table 2. In general, test and control groups were commonly characterized by low median PI scores at both patient ( 0.00 vs. $0.21 ; p=0.093)$ and implant levels (0.17 vs. 0.17 ), respectively.

Marked differences between test and control groups were noted for median BOP scores, reaching statistical significance at the patient level $(0.0$ vs. $25.0 \% ; p=0.023)$.

Similarly, the test group was associated with markedly lower median PD values at both patient ( 2.33 vs. 2.83 $\mathrm{mm} ; p=0.001)$ and implant levels $(2.33$ vs. $2.83 \mathrm{~mm})$, respectively.

Both groups revealed comparable median MR values at both patient $(0.0$ vs. $0.0 \mathrm{~mm} ; p=0.76)$ and implant levels $(0.0$ vs. $0.0 \mathrm{~mm})$, respectively (Table 2$)$.

\section{Prevalence of peri-implant diseases}

The frequency distribution of peri-implant diseases in the test and control groups at patient and implant levels is summarized in Tables 3 and 4.

According to the given case definitions, $66.7 \%$ of the patients in the control group and $47.4 \%$ of the patients in the test group were diagnosed with periimplant diseases. In the test group, the prevalence of peri-implant mucositis and peri-implantitis amounted to $42.1 \%$ and $5.3 \%$. In the control group, the corresponding values were $52.8 \%$ and $13.9 \%$, respectively (Table 3).

At the implant level, the prevalence of peri-implant mucositis and peri-implantitis amounted to $44.8 \%$ and $3.4 \%$ in the test group, and 52.7 and $9.1 \%$ in the control group, respectively (Table 4 ).

\section{Regression analysis}

Cross-tables depicting selected independent variables (PD, MR, and BOP values) and local factors (i.e., KM and Implant age) in both test and control groups are summarized in Tables 5 and 6 .

In the test group, the linear regression analysis failed to reveal any significant correlations between KM and the independent variables investigated.

In the control group, a significant correlation was noted between $\mathrm{KM}$ and $\mathrm{MR}$ values $\left(R^{2}=0.155 ; B=-\right.$ $0.072 ; p=0.003$ ) (Tables 5 and 6).

\section{Discussion}

The present cross-sectional analysis aimed at investigating the influence of soft-tissue volume grafting employing autogenous CTG simultaneous to implant placement on peri-implant tissue health and stability. Based on the clinical parameters investigated, it was noted that the patients in the test group revealed significantly lower BOP and PD scores when compared with those of the control group. This was associated with a lower prevalence of peri-implant diseases, particularly of patients diagnosed for periimplantitis. In this context, it must be emphasized that the latter assessment was based on recently established case definitions and considered previous examination data [11].

Basically, the present results do not confirm the findings of a recent systematic review and meta-analysis,

Table 1 Patient and implant site characteristics

\begin{tabular}{lll}
\hline & Control group ( $\boldsymbol{n}=\mathbf{5 5}$ implants) & Test group $(\boldsymbol{n}=\mathbf{2 9}$ implants \\
\hline Patient number & $n=36$ & $n=19$ \\
Patient age (years) & $62.21 \pm 14.41$ & $46.24 \pm 18.48$ \\
Patient gender (female/male) ( $n$ ) & $20 / 16$ & $13 / 6$ \\
Implant age years (mean \pm SD) (years) & $7.19 \pm 5.25$ & $4.16 \pm 2.06$ \\
Region upper jaw & & $1 / 4 / 25$ \\
$\quad$ Premolars/canine/incisives ( $)$ & $20 / 15 / 20$ & $3.4 / 10.3 / 86.2$ \\
Premolars/canine/incisives (\%) & $36.4 / 27.2 / 33.4$ & $29 / 0$ \\
Implant diameter, 3.5/4.5 (n) & $47 / 8$ & $100 / 0$ \\
Implant diameter, 3.5/4.5 (\%) & $85.5 / 14.5$ & \\
\hline
\end{tabular}


Table 2 Clinical parameters (mean \pm SD, median and 95\% Cl)

\begin{tabular}{|c|c|c|c|c|c|c|c|}
\hline \multirow[t]{2}{*}{ Clinical parameters } & \multicolumn{3}{|c|}{ Control group } & \multicolumn{3}{|l|}{ Test group } & \multirow[t]{2}{*}{$p$} \\
\hline & Mean \pm SD & Median & $95 \% \mathrm{Cl}$ & Mean \pm SD & Median & $95 \% \mathrm{Cl}$ & \\
\hline \multicolumn{8}{|l|}{ Plaque index } \\
\hline Patient-level & $0.33 \pm 0.36$ & 0.21 & $0.21-0.45$ & $0.18 \pm 0.28$ & 0.00 & $0.04-0.31$ & \multirow[t]{2}{*}{0.093} \\
\hline Implant-level & $0.35 \pm 0.38$ & 0.17 & $0.25-0.46$ & $0.23 \pm 0.32$ & 0.17 & $0.11-0.35$ & \\
\hline \multicolumn{8}{|c|}{ Bleeding on probing (\%) } \\
\hline Patient-level & $28.42 \pm 28.35$ & 25.0 & $18.82-38.01$ & $11.16 \pm 14.63$ & 0.00 & $4.11-18.21$ & \multirow[t]{2}{*}{0.023} \\
\hline Implant-level & $29.44 \pm 30.0$ & 17.0 & $21.30-37.57$ & $13.83 \pm 19.37$ & 0.00 & $6.46-21.20$ & \\
\hline \multicolumn{8}{|l|}{ Probing depth (mm) } \\
\hline Patient-level & $2.98 \pm 0.65$ & 2.83 & $2.76-3.20$ & $2.36 \pm 0.53$ & 2.33 & $2.10-2.61$ & \multirow[t]{2}{*}{0.001} \\
\hline Implant-level & $2.99 \pm 0.64$ & 2.83 & $2.81-3.16$ & $2.40 \pm 0.54$ & 2.33 & $2.19-2.61$ & \\
\hline \multicolumn{8}{|c|}{ Mucosal recession (mm) } \\
\hline Patient-level & $0.07 \pm 0.19$ & 0 & $0.00-0.13$ & $0.07 \pm 0.18$ & 0 & -0.02 to 0.15 & \multirow[t]{2}{*}{0.76} \\
\hline Implant-level & $0.07 \pm 0.25$ & 0 & $0.09-0.14$ & $0.09 \pm 0.21$ & 0 & $0.04-0.17$ & \\
\hline
\end{tabular}

since soft tissue grafting procedures by means of CTG were not associated with any significant differences in $\mathrm{BOP}$ or $\mathrm{PD}$ values as compared to control treatments [1]. The analysis was based on a total of 6 randomized $(n=2) /$ controlled clinical $(n=4)$ studies reporting on a total of 260 systemically and periodontally healthy patients over a mean follow-up period of 57 months [9, 12-16]. Except for one study [17], the implants were placed immediately and soft tissue grafting was accomplished either at implant placement $[9,12,15]$, or after a healing period of 3 months [13, 14, 16]. At test sites, the range of mean BOP values was $20-35 \%$ at baseline and amounted to $20-56 \%$ at follow-up [14-17]. The corresponding values at control sites were $21-40 \%$ at baseline and $33-46 \%$ at follow-up [1]. A total of five studies [9, 13-16] failed to identify any significant effects of softtissue volume grafting on mean PD values. In particular, at test sites, the range of mean PD values was 2.50-3.45 $\mathrm{mm}$ at baseline and amounted to $3.67-4.09 \mathrm{~mm}$ at follow-up. At control sites, these values were 2.50-3.20 $\mathrm{mm}$ at baseline and 3.20-3.97 $\mathrm{mm}$ at follow-up [1]. One study focusing on immediate implant placement with simultaneous soft-tissue volume grafting reported on significantly lower PD values at test sites when compared with control sites [12].

Table 3 Prevalence of peri-implant disease (patient level)

\begin{tabular}{lllll}
\hline & Control group & $\%$ & Test group & $\%$ \\
\hline Healthy & 12 & 33.3 & 10 & 52.6 \\
Peri-implant mucositis & 19 & 52.8 & 8 & 42.1 \\
Peri-implantitis & 5 & 13.9 & 1 & 5.3 \\
\hline
\end{tabular}

The meta-analysis failed to reveal any significant differences in either plaque, BOP, or PD scores (i.e., changes or endpoint values) between test and control groups. However, significantly less marginal bone loss over time was observed with the use of CTG $[n=2$; WMD $=0.110 ; 95 \%$ CI $(0.067 ; 0.154) ; p<0.001]$ when compared to sites without grafting [1].

The discrepancy noted between the present analysis and the aforementioned systematic review may, at least in part, be explained by the fact that the included studies $[9,12-16]$ did not consider BOP or PD as primary outcomes measures. Accordingly, the power of these studies may not have been sufficient to rule out potential differences between groups. Moreover, it needs to be emphasized that none of the evaluated studies [9, 12-16] used case definitions for the evaluation of the occurrence of peri-implant diseases [1].

The present study did not consider to routinely take radiographs during follow-up, but just limited the indication to those patients exhibiting clinical signs of peri-implant tissue inflammation [18]. Accordingly, the influence of soft-tissue volume grafting procedures on marginal bone level changes could not be assessed.

When further evaluating the present data, it was also noted that, in contrast to implants of the test group,

Table 4 Prevalence of peri-implant disease (implant level)

\begin{tabular}{lllll}
\hline & Control group & \% & Test group & $\%$ \\
\hline Healthy & 21 & 38.2 & 15 & 51.7 \\
Peri-implant mucositis & 29 & 52.7 & 13 & 44.8 \\
Peri-implantitis & 5 & 9.1 & 1 & 3.4 \\
\hline
\end{tabular}


Table 5 Test group ( $n=29$ implants). Cross-tables of BOP/PD/ MR values and (1) KM and (2) implant age (months)

\begin{tabular}{|c|c|c|c|}
\hline \multirow[t]{2}{*}{ 1) BOP values } & \multicolumn{3}{|l|}{ KM } \\
\hline & $<2 \mathrm{~mm}$ & \multicolumn{2}{|l|}{$\geq 2 \mathrm{~mm}$} \\
\hline 0 & 0 & \multicolumn{2}{|l|}{15} \\
\hline$<33 \%$ & 0 & \multicolumn{2}{|l|}{8} \\
\hline$<67 \%$ & 0 & \multicolumn{2}{|l|}{5} \\
\hline \multirow[t]{3}{*}{$>67 \%$} & 0 & 1 & \\
\hline & \multicolumn{3}{|c|}{ Implant age } \\
\hline & $1-24$ & $24-60$ & $>60$ \\
\hline 0 & 2 & 7 & 6 \\
\hline$<33 \%$ & 2 & 3 & 3 \\
\hline$<67 \%$ & 0 & 3 & 2 \\
\hline$>67 \%$ & 0 & 1 & 0 \\
\hline \multirow[t]{2}{*}{ 2) PD values } & \multicolumn{3}{|l|}{ KM } \\
\hline & $<2 \mathrm{~mm}$ & \multicolumn{2}{|l|}{$\geq 2 \mathrm{~mm}$} \\
\hline $1-3 \mathrm{~mm}$ & 0 & \multicolumn{2}{|l|}{22} \\
\hline $4-6 \mathrm{~mm}$ & 0 & \multicolumn{2}{|l|}{7} \\
\hline \multirow[t]{3}{*}{$>7 \mathrm{~mm}$} & 0 & 0 & \\
\hline & \multicolumn{3}{|c|}{ Implant age } \\
\hline & $1-24$ & $24-60$ & $>60$ \\
\hline $1-3 \mathrm{~mm}$ & 3 & 11 & 8 \\
\hline $4-6 \mathrm{~mm}$ & 1 & 3 & 3 \\
\hline$>7 \mathrm{~mm}$ & 0 & 0 & 0 \\
\hline \multirow[t]{2}{*}{ 3) $M R$} & \multicolumn{3}{|l|}{ KM } \\
\hline & $<2 \mathrm{~mm}$ & \multicolumn{2}{|l|}{$\geq 2 \mathrm{~mm}$} \\
\hline $0 \mathrm{~mm}$ & 0 & \multicolumn{2}{|l|}{24} \\
\hline \multirow[t]{3}{*}{$>0 \mathrm{~mm}$} & 0 & 5 & \\
\hline & \multicolumn{3}{|c|}{ Implant age } \\
\hline & $1-24$ & $24-60$ & $>60$ \\
\hline $0 \mathrm{~mm}$ & 4 & 11 & 9 \\
\hline$>0 \mathrm{~mm}$ & 0 & 3 & 2 \\
\hline
\end{tabular}

control sites revealed a significant correlation between $\mathrm{KM}$ and MR values. In this context, it must be emphasized that a major drawback of the present study was the lack of a quantification of the horizontal mucosal thickness (i.e., biotype) during follow-up. That was due to the fact that the assessment of the biotype is challenging at diseased implant sites, since the inflammatory lesion is inevitably associated with an increase in mucosal thickness [19]. As a consequence of the notable prevalence of peri-implant diseases in both groups, it may have been impossible to estimate true changes of the biotype during follow-up.

Nevertheless, the findings of the regression analysis corroborate the results of previous studies also indicating that at implant sites exhibiting a healthy periimplant mucosa, a thick tissue biotype was associated
Table 6 Control group ( $n=55$ implants). Cross-tables of BOP/ $\mathrm{PD} / \mathrm{MR}$ values and (1) KM and (2) implant age (months)

\begin{tabular}{llll}
\hline $\mathbf{1 )}$ BOP values & KM & & \\
& $<2 \mathrm{~mm}$ & $2 \mathrm{~mm}$ & \\
$\mathbf{0}$ & 1 & 20 & \\
$<\mathbf{3 3} \%$ & 0 & 12 & \\
$<\mathbf{6 7 \%}$ & 2 & 10 & \\
$>\mathbf{6 7 \%} \%$ & 2 & & $>60$ \\
& Implant age & $24-60$ & 10 \\
& $1-24$ & 5 & 2 \\
$\mathbf{0}$ & 6 & 5 & 10 \\
$<\mathbf{3 3} \%$ & 1 & 4 & 8 \\
$<\mathbf{6 7 \%}$ & 0 & 4 &
\end{tabular}

2) PD values

KM

$<2 \mathrm{~mm} \quad \geq 2 \mathrm{~mm}$

1-3 mm

238

4-6 mm

$>7 \mathrm{~mm}$

3

0

12

0

Implant age

$1-24 \quad 24-60 \quad>60$

$1-3 \mathrm{~mm}$

4-6 $\mathrm{mm}$

7

0

$>7 \mathrm{~mm}$

0

3) $M R$

KM

$0 \mathrm{~mm}$

$<2 \mathrm{~mm}$

$\geq 2 \mathrm{~mm}$

$>0 \mathrm{~mm}$

2

46

3

4

Implant age

\begin{tabular}{lll}
$1-24$ & $24-60$ & $>60$ \\
7 & 16 & 25 \\
0 & 2 & 5 \\
\hline
\end{tabular}

with a lower frequency of facial soft-tissue recessions (i.e., MR values) over time when compared with sites exhibiting a thin biotype $[6,20]$.

In conclusion and within its limitations, the present study has indicated that simultaneous soft-tissue grafting using CTG had a beneficial effect on the maintenance of peri-implant health.

Acknowledgements

Not applicable.

Authors' contributions

$\mathrm{KO}, \mathrm{AR}$, and FS have made substantial contributions to study conception and interpretation of data as well as manuscript drafting. AB, PP, and MEGV were involved in the data assessment and analysis. $\mathrm{KO}, \mathrm{AR}$, and FS contributed to the data interpretation and manuscript drafting. All authors read and approved the final manuscript. 


\section{Funding}

The study was self-funded by the authors own departments.

\section{Availability of data and materials}

Not applicable.

\section{Ethics approval and consent to participate}

The study protocol was approved by the Goethe University (Frankfurt, Germany) ethics committee (register number: 78/18).

\section{Consent for publication}

Not applicable.

\section{Competing interests}

The authors Karina Obrej, Ausra Ramanauskaite, Frank Schwarz, Amira Begic, Puria Parvini, and Maria Elisa Galarraga-Vinueza declare that they have no competing interests.

\section{Author details}

'Department of Oral Surgery and Implantology, Johann Wolfgang Goethe-University Frankfurt, Carolinum, Theodor-Stern-Kai 7; Building 29, 60596 Frankfurt, Germany. ${ }^{2}$ Federal University of Santa Catarina (UFSC), SC, Florianópolis, Brazil.

Received: 15 October 2020 Accepted: 25 January 2021

Published online: 23 February 2021

\section{References}

1. Thoma DS, et al. Effects of soft tissue augmentation procedures on periimplant health or disease: a systematic review and meta-analysis. Clin Oral Implants Res. 2018:29(Suppl 15):32-49.

2. Roos-Jansaker AM, et al. Nine- to fourteen-year follow-up of implant treatment. Part III: factors associated with peri-implant lesions. J Clin Periodontol. 2006;33(4):296-301.

3. Roccuzzo M, Grasso G, Dalmasso P. Keratinized mucosa around implants in partially edentulous posterior mandible: 10-year results of a prospective comparative study. Clin Oral Implants Res. 2016;27(4):491-6.

4. Sanz-Martin I, Regidor E, Navarro J, Sanz-Sanchez I, Snz M, Ortiz-Vigon A, Factors associated with the presence of peri-implant buccal soft tissue dehiscences. A case-control study. J Clin Periodontol. 2020. https://doi.org/ 10.1002/JPER.19-0490.

5. Chen ST, et al. Immediate implant placement postextraction without flap elevation. J Periodontol. 2009;80(1):163-72.

6. Evans CD, Chen ST. Esthetic outcomes of immediate implant placements. Clin Oral Implants Res. 2008;19(1):73-80

7. Kan JY, et al. Facial gingival tissue stability following immediate placement and provisionalization of maxillary anterior single implants: a 2- to 8-year follow-up. Int J Oral Maxillofac Implants. 2011;26(1):179-87.

8. van Nimwegen WG, et al. Immediate placement and provisionalization of implants in the aesthetic zone with or without a connective tissue graft: a 1-year randomized controlled trial and volumetric study. Clin Oral Implants Res. 2018;29(7):671-8.

9. Yoshino $\mathrm{S}$, et al. Effects of connective tissue grafting on the facial gingival level following single immediate implant placement and provisionalization in the esthetic zone: a 1-year randomized controlled prospective study. Int J Oral Maxillofac Implants. 2014;29(2):432-40.

10. Akcali A, et al. What is the effect of soft tissue thickness on crestal bone loss around dental implants? A systematic review. Clin Oral Implants Res. 2017; 28(9):1046-53

11. Berglundh T, et al. Peri-implant diseases and conditions: consensus report of workgroup 4 of the 2017 World Workshop on the Classification of Periodontal and Peri-Implant Diseases and Conditions. J Clin Periodontol. 2018;45(Suppl 20):S286-91.

12. Bianchi $A E$, Sanfilippo F. Single-tooth replacement by immediate implant and connective tissue graft: a 1-9-year clinical evaluation. Clin Oral Implants Res. 2004;15(3):269-77.

13. Bienz SP, et al. Volumetric changes at pontic sites with or without soft tissue grafting: a controlled clinical study with a 10-year follow-up. J Clin Periodontol. 2017:44(2):178-84.

14. Fenner $\mathrm{N}$, et al. Long-term clinical, technical, and esthetic outcomes of allceramic vs. titanium abutments on implant supporting single-tooth reconstructions after at least 5 years. Clin Oral Implants Res. 2016;27(6):71623.

15. Migliorati M, et al. Clinical and aesthetic outcome with post-extractive implants with or without soft tissue augmentation: a 2-year randomized clinical trial. Clin Implant Dent Relat Res. 2015;17(5):983-95.

16. Cosyn J, et al. A 5-year prospective study on single immediate implants in the aesthetic zone. J Clin Periodontol. 2016;43(8):702-9.

17. Bienz SP, et al. Volumetric changes and peri-implant health at implant sites with or without soft tissue grafting in the esthetic zone, a retrospective case-control study with a 5-year follow-up. Clin Oral Implants Res. 2017; 28(11):1459-65.

18. Lindhe J, Meyle J. and D.o.E.W.o.P. Group, Peri-implant diseases: consensus report of the Sixth European Workshop on Periodontology. J Clin Periodontol. 2008;35(8 Suppl):282-5.

19. Schwarz F, Claus C, Becker K. Correlation between horizontal mucosal thickness and probing depths at healthy and diseased implant sites. Clin Oral Implants Res. 2017;28(9):1158-63.

20. Nisapakultorn $\mathrm{K}$, et al. Factors affecting soft tissue level around anterior maxillary single-tooth implants. Clin Oral Implants Res. 2010;21(6):662-70.

\section{Publisher's Note}

Springer Nature remains neutral with regard to jurisdictional claims in published maps and institutional affiliations.

\section{Submit your manuscript to a SpringerOpen ${ }^{\circ}$ journal and benefit from:}

- Convenient online submission

- Rigorous peer review

- Open access: articles freely available online

- High visibility within the field

- Retaining the copyright to your article

Submit your next manuscript at $>$ springeropen.com 